\title{
Natürliches Licht für optimale Sicht
}

Dentsply Sirona Treatment Centers stellt eine neue Behandlungsleuchte vor: LEDview Plus sorgt dank integrierter mehrfarbiger LEDs für ein naturnahes Licht, das gesundes Sehen und die perfekte und gleichmäßige Ausleuchtung der Mundhöhle ermöglicht. Dadurch fällt die Beurteilung von Gingiva und Zahnhartsubstanz leichter und macht die Behandlung somit sicherer. Das ca. $200 \times 100$ mm große Lichtfeld bietet einwandfreie Sicht ohne nachjustieren zu müssen - jederzeit scharf und schattenfrei. Eine Besonderheit ist der Komposit-Modus: Hierbei werden gezielt die Blaulichtanteile reduziert. Auf diese Weise wird ein vorzeitiges Aushärten von lichthärtendem Füllmaterial verhindert. Die Materialien können bei optimaler Sicht ohne Zeitdruck verarbeitet werden. Behandler können zwischen sieben Helligkeitsstufen zwischen 5000 und 40000 Lux wählen und dabei 3 unterschiedliche Farbtemperaturstufen (4600 K - $6200 \mathrm{~K}$ ) passend für jede vorliegende Behandlungssituation einstellen. Die Farbwiedergabequalität bleibt dabei immer konstant. LEDview Plus ist als Op-

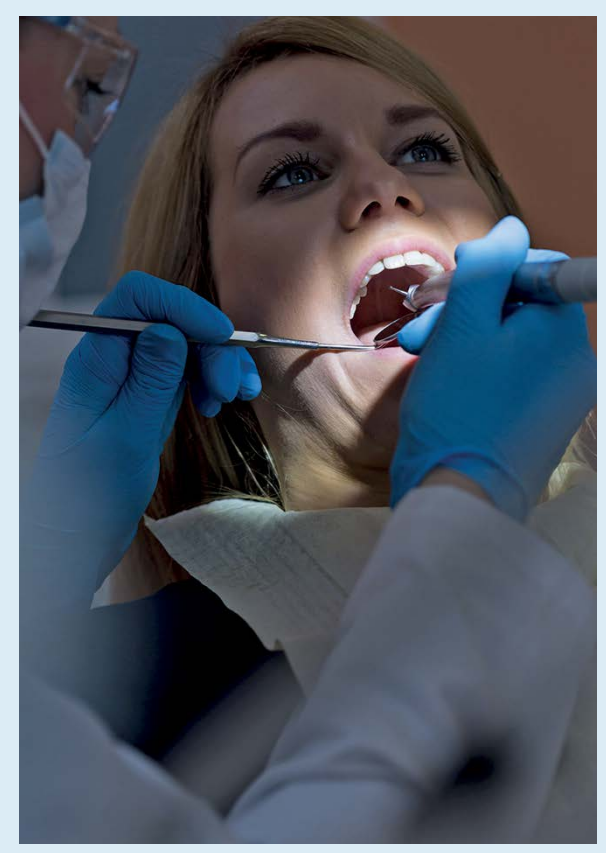

tion für die Behandlungseinheiten INTEGO, SINIUS und TENEO ab sofort erhältlich.

Nach einer Pressemitteilung des Dentsply-Sirona Treatment Center, A - Wals bei Salzburg 